\title{
Epidemia de sarampo e trabalho escravo no Grão-Pará (1748-1778)
}

\author{
Antonio Otaviano Vieira Junior ${ }^{\star}$ \\ Roberta Sauaia Martins ${ }^{\star *}$
}

0 artigo apresenta o impacto populacional provocado pela epidemia de sarampo (1748-1750) na capitania do Grão-Pará e sua relação com o processo de inserção da mão de obra escrava africana. A análise é fundamentada na documentação produzida no século XVIII, levantada em diferentes arquivos brasileiros e portugueses, incluindo correspondências oficiais, crônicas, memórias, mapas populacionais e listagens de mortos pela epidemia. A documentação serial foi posta em base de dados, construída a partir das 80 listagens de mortos pelo sarampo, o que permitiu uma análise do impacto demográfico da epidemia. Concomitantemente, a contagem populacional das vilas e povoações da capitania, do terceiro quartel do século XVIII, compôs uma segunda base de dados e auxiliou na compreensão da distribuição interna de escravos africanos. 0 ponto de interseção entre as bases de dados é formado pelo conjunto da documentação histórica administrativa, que trata dos efeitos da epidemia e das possibilidades de solução da crise de mão de obra - ocasionada pela alta mortalidade de indígenas. 0 estudo procura mostrar não apenas a mortalidade causada pelo sarampo, mas também a construção de uma política para a inserção de escravos africanos na região. Para tanto abordam-se a epidemia em Belém, a importância do trabalho indígena para os colonos, o número de mortos e a distribuição da mortalidade considerando espaço e sazonalidade (meses e anos). Também se discutem a luta entre projetos para sanar a demanda de mão de obra, gerada pela alta mortalidade do sarampo, e a política de inserção de escravos africanos para combater a carência de trabalhadores, bem como a distribuição desses escravos na capitania.

Palavras-chave: Sarampo. Índios. Escravos. Amazônia. Grão-Pará

\footnotetext{
* Universidade Federal do Pará - UFPA, Belém-PA, Brasil (otaviano@ufpa.br).

** Universidade Federal do Pará - UFPA, Belém-PA, Brasil (robertasauaia@hotmail.com).
} 


\section{Epidemia de sarampo}

Epidemias marcaram a história do contato entre a população autóctone da América e europeus, tornando-se um dos fatores que explicam a diminuição significativa da população americana original (LIVI-BACCI, 2001; GUERRA, 1993; DOBYNS, 1966). Na Amazônia colonizada pelos portugueses não foi diferente. Ao longo dos séculos XVII e XVIII, a região deparou-se com diferenciados cenários epidêmicos (1649-1652, 1661-1662, 1690, 17241725 e 1737-1740), o que interferia na própria organização produtiva, pois afetava o trabalho compulsório e a composição demográfica das áreas atingidas (CHAMBOULEYRON et al., 2011; GUZMÀN, 2012).

Entre 1748 e 1750, mais uma epidemia aportou no Estado do Maranhão e Grão-Pará. ${ }^{1}$ Esse surto ficou conhecido por "sarampo grande", agregando um adjetivo que destacava sua força quando comparada com epidemias anteriores, como bem deixou registrado o tenente Teodosio Chremont:

[...] foram vistos lugares naquele rio (Rio Branco) que, sendo antes habitado de inumerável gentio, então não mostravam outros sinais do que os ossos dos corpos dos que haviam perecidos [...] Na cidade e em todo o Estado, fez tal estrago que, por isso, mereceu o distintivo de ser chamado de o sarampo grande (FERREIRA, 1781, grifo nosso).

Entre as várias vilas, aldeamentos e povoações afetados pelo sarampo, Belém do Grão-Pará registrou as mais detalhadas lembranças acerca do impacto dessa epidemia. Lembranças das mortes que deixaram rastros desde os sertões até a cidade. Lembranças das lamentações e flagelos públicos, imbuídos "para que o Árbitro do mundo, movido aos empenhos da contrição, e da suplica, abrandado o rigor de sua justificada vingança, usasse das branduras da sua misericórdia infinita". ${ }^{2}$ Lembranças das ordens religiosas que se movimentavam e da cidade que assistiu um número maior de novenas, missas, procissões, autoflagelos e emocionantes sermões. Rotina de penitências, em que as ordens religiosas pareciam disputar quem teria maior capacidade de clamor e sacrifício para abrandar a fúria da epidemia. ${ }^{3}$

Além dos rituais católicos, nas ruas de Belém também se viam cadáveres insepultos, conduzidos para as redondezas da cidade (o Piri e o São José), jogados nos rios ou nas ruas "expostos à misericórdia dos vivos". Também não era raro encontrar pessoas acometidas de "terríveis assaltos se congregarão os impulsos de vômitos de sangue, e diarrheas". ${ }^{4}$

\footnotetext{
${ }^{1}$ A partir de 1751 o Estado do Maranhão e Grão-Pará, cuja capital era São Luiz, passa a ser chamado de Estado do Grão-Pará e Maranhão, capital Belém. Não foi apenas uma mudança de nome, mas também uma valorização administrativa do Grão-Pará.

2 Biblioteca Nacional de Portugal. Noticia verdadeyra do terrivel contagio, que desde Outubro de 1748. ate o mez de Mayo de 1749. tem reduzido a notavel consternaçaõ todos os Certões, terras, e Cidade de Bellém, e Graõ Pará, extrahida das mais fidedignas memorias / [Manuel Ferreira Leonardo].

${ }^{3}$ Biblioteca Nacional de Portugal. Noticia verdadeyra do terrivel contagio, que desde Outubro de 1748. ate o mez de Mayo de 1749. tem reduzido a notavel consternaçaõ todos os Certões, terras, e Cidade de Bellém, e Graõ Pará, extrahida das mais fidedignas memorias / [Manuel Ferreira Leonardo].

${ }^{4}$ Biblioteca Nacional de Portugal. Noticia verdadeyra do terrivel contagio, que desde Outubro de 1748. ate o mez de Mayo de 1749. tem reduzido a notavel consternaçaõ todos os Certões, terras, e Cidade de Bellém, e Graõ Pará, extrahida das mais fidedignas memorias / [Manuel Ferreira Leonardo].
} 
Ainda outro aspecto poderia compor esse cenário de lembranças: a fome que assolou Belém, havendo “um excesso de carestia”. 0 então governador do Maranhão relatou ao rei o estado preocupante da alimentação dos moradores:

[...] o formidável contagio de que dey conta a Vossa Excelencia nos Navios passados [...] está presente afligindo todos os moradores desta Capitania [Grão-Pará] com os seus efeitos, pois reduzindo todos a mayor consternação com a morte dos seus Escravos, não tem quem the apanhe os frutos das fazendas, q são todos os seus haveres, nem que lhe faça as maes Lavouras [...] e por esta causas se tem experimentado hua fome considerável de farinha. ${ }^{5}$

Além da fome, o trecho citado mais uma vez reforça a importância do trabalho indígena (naquele período, escravo era sinônimo de escravo índio) e ainda pontua que esse contingente populacional foi o mais atingido pelo sarampo, gerando desdobramento para a produção de alimentos dos moradores. No rastro da morte causada pela doença, vinham o desabastecimento de comida, a possível diminuição dos produtos de exportação e o pedido urgente para inserção da mão de obra escrava africana. ${ }^{6}$

\section{Epidemia, mão de obra e reconfiguração de cotidianos}

Os impactos da epidemia de sarampo estavam associados a um importante indicador demográfico: a mortalidade, que tem efeitos sobre a evolução demográfica, social e econômica de uma região (CANCHO, 1981, p. 24). A demografia histórica vem destacando as repercussões de epidemias na composição da dinâmica populacional, principalmente quando articuladas a períodos de fome, o que corrobora a ideia de que os estudos não devem se resumir ao total absoluto de mortos, procurando analisar os segmentos (etnia, sexo, idade, ofício...) mais atingidos pela doença. Também se deve considerar que, embora a epidemia tenha uma duração relativamente curta, seus efeitos no índice de crescimento de uma população podem ser mais duradouros (WRIGLEY; SHOFIELD, 1981, p. 413; GLASS; EVERSLEY, 1965, p. 52-55).

Livi-Bacci (2006) problematizou o papel das epidemias, em especial das novas doenças, na diminuição da população americana, ao afirmar que o alcance de uma epidemia não se resume a um modelo estático, abrangendo dados específicos como a razão de contágio, de sobrevivência e a capacidade da sociedade de se organizar para combater a doença. E mais, o decréscimo da população indígena pós-contato não pode ser resumido às epidemias, o que seria desprezar elementos fundamentais da relação entre autóctones e colonizadores: imposição de modelo produtivo e das guerras de conquistas (LIVI-BACCI, 2006).

0 presente estudo parte do pressuposto de que a epidemia de sarampo (1748-1750) não foi o único fator, mas significou mudanças importantes no cenário demográfico do Grão-Pará, o que possibilita enveredar pela história da população da região. As lembranças

\footnotetext{
${ }^{5}$ Arquivo Histórico Ultramarino de Portugal, Projeto Resgate, Capitania do Grão-Pará, 13 de agosto de 1750, fl. 1.

${ }^{6}$ Arquivo Histórico Ultramarino de Portugal, Projeto Resgate, Capitania do Grão-Pará, 13 de agosto de 1750, fl. 1.
} 
e notícias do sarampo podem servir para não resumirmos a região aos desígnios administrativos, nem à exploração das drogas do sertão, nem à exportação de cacau e de café e nem ao confronto entre ordens religiosas e colonos. Enfim, trata-se da possibilidade de problematizarmos sua construção histórica a partir do prisma da dinâmica populacional.

Os relatos e as memórias anteriormente destacados apontam para a presença importante e cotidiana de um fator populacional: o Estado do Maranhão e Grão-Pará iniciou a segunda metade do século XVIII enfrentando os impactos demográficos de uma epidemia de sarampo. No depoimento do governador do Estado, Francisco Pedro Gurjão, fica bastante claro que o principal desdobramento do, segundo ele, "formidável contágio" era demográfico. A morte de índios poderia não só ameaçar a produção exportadora de cacau e café, como também diminuir dízimos reais, ameaçando a própria subsistência dos moradores.

No Conselho Ultramarino (órgão de fiscalização e uniformização do Império português), ecoaram as reclamações do governador, que afirmou em maio de 1750: “o Governador do Maranhão da conta do deplorável estado a que se acham reduzidas aquelas Capitanias como grande número de índios [grifo nosso] que devorou o contagio que ali contaminou". ${ }^{7}$ Não foram encontrados documentos em que se destacasse a morte de brancos pelo sarampo. A documentação é muita clara: a maioria significativa de mortos era composta de índios.

Assim, os diferentes relatos apontavam para a diminuição da mão de obra indígena como consequência imediata da epidemia de sarampo. Uma queixa que permeava diferentes discursos - de governadores, moradores e religiosos - era o número de índios mortos. Isso traz problemas metodológicos relacionados à imprecisão das contagens numéricas da época. Livi-Bacci (2012) discute a dificuldade de produzir estudos demográficos acerca das sociedades indígenas na Amazônia colonial. ${ }^{8}$

\section{A epidemia em números}

Trabalhar com a demografia histórica indígena para o período colonial sempre é um desafio. Nem mesmo existe consenso acerca do número de índios no Brasil antes do "descobrimento". Ainda nos dias atuais há "pouco desenvolvimento da área da demografia dos povos indígenas no Brasil”, o que em parte pode ser explicado pela dificuldade de obtenção de dados relacionados ao passado indígena (PAGLIARO; AZEVEDO; SANTOS, 2005, p. 4).

Embora esse artigo não tenha a intenção de fazer um estudo detalhado da demografia indígena na capitania do Grão-Pará, é necessário analisar os números relacionados à alta mortalidade do sarampo, o que, consequentemente, leva à contextualização da produção das informações, em especial dos números que são vinculados pela documentação pesquisada.

\footnotetext{
${ }^{7}$ Arquivo Histórico Ultramarino de Portugal, Projeto Resgate, Capitania do Grão-Pará, 16 de maio de 1750.

${ }^{8} 0$ autor afirma que: "se le popolazioni del Grande Fiume [rio Amazonas] rappresentano um inferno - o um purgatório - per il demógrafo, esse sono um paradiso pel l'antropologo." (LIVI-BACCI, 2012, p. 143). Isso em parte se justifica pela dispersão da população em um vasto território, pela fluidez na definição de grupos e pela pouca instrumentação da época para produzir contagens mais confiáveis.
} 
O primeiro ponto diz respeito ao fundo documental que guarda parte significativa das fontes analisadas: o Arquivo Histórico Ultramarino Português, acervo de documentos da capitania do Grão-Pará, em Lisboa. 0 Conselho Ultramarino foi criado em 1642, instalado em 1643 e extinto em 1833. Sua principal finalidade era a uniformização e fiscalização de todo o Império português, desde a África até a América, passando pela Índia. 0 Arquivo Histórico Ultramarino preserva até hoje o acervo riquíssimo de documentos administrativos produzidos por esse Conselho.

Esse arquivo possibilitou o acesso a uma série de documentos que pautaram a presente análise. Trata-se de documentos produzidos nos dois lados do Atlântico, por diferentes agentes. Colonos, religiosos e administradores teciam suas reclamações e sugestões, tendo como ponto central a epidemia de sarampo. Por sua vez, os conselheiros apontavam possíveis soluções e criavam alguns questionamentos. Do Grão-Pará surgia um conjunto de listagens e balanços de mortos, todos agregados às ininterruptas queixas acerca da epidemia. Tais anexos traziam na sua composição uma série de contagens de mortos especificamente relacionados ao sarampo, pois seriam esses dados que corroborariam os pedidos e lamentos feitos desse lado do oceano. Assim, deve-se ter claro que tais dados foram arrolados por religiosos, colonos e administradores, que tinham como objetivo principal comover o Conselho Ultramarino para permitir a entrada de escravos africanos e/ou autorizar a intensificação da montagem de Tropas de Resgate. ${ }^{9}$

Entre as autoridades do período, a mais constante na elaboração de reclamações era o governador Francisco Pedro Gurjão, que apostava na contagem dos mortos para legitimar posições políticas de exploração de mão de obra e ocupação de espaço. Sua correspondência possibilitou, apesar da desconfiança, uma aproximação das estimativas relacionadas ao impacto da doença. Francisco Pedro Gurjão era governador do Estado do Maranhão e Grão-Pará (1747-1751) durante a epidemia, e tinha ligação direta com Lisboa - fidalgo, Cavaleiro da Ordem de Cristo e nomeado governador pelo rei D. João V. No trecho apresentado a seguir, fica claro que o governador tentava convencer Lisboa da força do contágio do sarampo. Nesse sentido, ele apostava numa suposta precisão dos dados, a qual deparar-se-ia com limites metodológicos - quando comparados com os atuais métodos de análise demográfica -, pois somente em fins do século XVIII foram criados os pressupostos essenciais que orientariam os sistemas nacionais de estatísticas nos países europeus (BANDEIRA, 2004, p. 39).

Apesar dos limites da contagem (por exemplo, não eram apresentados dados da população total da capitania ou não se trabalhava com percentuais), o governador Gurjão apostava nos números como ferramenta de convencimento acerca do impacto do sarampo. Era evidente o confronto com intrigas políticas entre colonos e religiosos, que tentavam manobrar por interesses próprios as representações das consequências da doença:

\footnotetext{
${ }^{9}$ Tropas de Resgates eram expedições militares que visavam negociar com algumas tribos aliadas índios que haviam sido presos em guerras intertribais, os chamados "índios de corda". Com o passar dos anos, tais tropas eram simplesmente de apreensão de índios dispersos na floresta, fossem ou não "índios de corda".
} 
Consta-me que houve quem com sinistras informações movido só de conveniências particulares quis capacitar a Vossa Majestade de que o Contagio não tinha sido com aquella vehemencia q Eu representava; porem Senhor, como a minha obrigação, he muy separada do defeito de encarecido entrey na deligencia de saber formalmente o numero de pessoas que morrião [grifo nosso] [...] estou bem certo que todos os Sugeitos que nesta matéria / como Eu/ falarem sem maiz paxão que a verdade não são de diferir dessa conta em que procurey com toda a exacção ser bem informado. ${ }^{10}$

Segundo o governador, na cidade de Belém, contabilizavam-se 10.777 mortes nas aldeias indígenas e nas fazendas dos religiosos. Somavam-se a esse número 7.600 índios que morreram de sarampo e estavam trabalhando para os moradores da cidade. E ainda faltaria contabilizar as inúmeras fazendas da capitania e as Vilas de Vigia, Bragança e Cametá, além das pessoas dispersas pelo "sertão" [floresta]. E que "somando a todas hão delegar a quarenta mil". ${ }^{11}$

Esses dados ganharam ressonância na obra do jesuíta João Daniel, que assumiu a estimativa de 30.000 índios mortos nas missões, como "testemunhou um governador" (DANIEL, 1975, p. 283). Não foi uma contagem feita pelo próprio João Daniel, mas sim dados que impregnaram a sua memória a partir dos números levantados por Gurjão.

Ainda com base na contagem feita pelo governador Francisco Pedro Gurjão, encontrou-se um número de mortos pelo sarampo restrito aos trabalhadores de algumas das fazendas de religiosos, além dos escravos indígenas que estavam a serviço dos moradores da dita cidade. Essa somatória foi chamada pelo próprio governador de Resumo de Mortos, alcançando o total de 18.377.

Mas Gurjão extrapolou essa contagem e produziu uma estimativa, considerando o alcance da epidemia em outras regiões da capitania. Ele apresentou à Coroa um quadro geral mais assustador: 40.000 mortos. Essa informação parece pouco confiável, pois mais da metade da estimativa apoiou-se em suposição, o que nos fez descartá-la para efeito de análise quantitativa.

Em outra posição política, poder-se-ia encontrar um dos grupos que se contrapunham a Gurjão, formado pelos vereadores da cidade de Belém. A Câmara de vereadores se estabelecia no mundo colonial português enquanto força que, muitas vezes, limitava a própria ingerência de Lisboa na execução das ordens reais (BICALHO, 2003, p. 342). A tensão entre esse grupo e o governador, que representava as diretrizes do Conselho Ultramarino, se dava em função da solução para a crise de mão de obra instalada pelo sarampo: o governador havia indeferido o pedido de permissão emergencial para apreensão de índios nos sertões por meio da montagem de novas Tropas de Resgate. Para a Câmara de Belém, a solução seria a intensificação da escravização indígena e a entrada de escravos africanos. Pelo menos no discurso, Gurjão defendia somente a entrada de braços africanos. Mas ambos concordavam quanto à alta mortalidade gerada pela doença e aos números como instrumento comprovador desse impacto.

\footnotetext{
${ }^{10}$ Arquivo Histórico Ultramarino de Portugal, Projeto Resgate, Capitania do Grão-Pará 13 de agosto de 1750.

${ }^{11}$ Arquivo Histórico Ultramarino de Portugal, Projeto Resgate, Capitania do Grão-Pará 13 de agosto de 1750.
} 
Trabalhar com dados produzidos por um grupo político opositor ao governador significa, para a pesquisa, a possibilidade de problematizar a contagem vinculada por Francisco Gurjão. Uma problematização feita à luz de seus contemporâneos. Assim, em uma carta assinada pelos vereadores de Belém, na tentativa de legitimar o pedido de formação de expedições para apreensão de índios no sertão, os oficiais da Câmara da cidade sublinharam a ideia da gravidade do impacto demográfico da epidemia. Um mês após o envio da carta do governador Gurjão, eles continuavam reclamando e diziam que somente as Tropas de Resgate não seriam suficientes:

A mayor parte dos Engenhos, e mais Fazendas se vem hoje despovoadas, e como este remédio não seja ainda bastante para a reforma de tantos milhares de escravos que parecerão nesta tão abominável peste rogamos a Vossa Majestade se digne mandar algum navio de pretos para se repartirem com os moradores $[. . .]^{12}$

Para a análise quantitativa das mortes causadas pelo sarampo, essa carta tinha um conjunto de dados de suma importância. Os vereadores anexaram à missiva uma série de listagens elaboradas por diferentes administradores religiosos de povoações indígenas, em que era especificada a quantidade de mortos pelo sarampo em suas respectivas povoações. As listagens ajudam a minimizar eventual hipertrofia do número de mortos e a manipulação política da epidemia, pois foram produzidas por diferentes religiosos e enviadas entre 1748 e 1750, não estando sob a tutela de um único administrador. Eram de diferentes formatos. Algumas eram mais sintéticas, como a elaborada pelo prior de Nossa Senhora do Monte do Carmo, em Belém: “certifico q' da peste de sarampo faleceram trezentas e doze pessoas entre homens, mulheres, rapazes e raparigas todas do gentio da

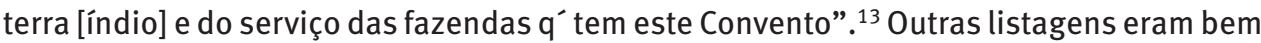
mais detalhadas. 0 comissário do Carmo, visitador das missões dos Rios Negro, Solimões, Cambebas e Japurâ afirmou:

q revendo os livros q servem da lista da gente de q consta haver nas ditas missões achei ter falecido do contagio de sarampo e dezertado por cauza do mesmo contagio agente seguinte: Nas aldeyas do Rio Negro da aldeia de santo Elias do Jaú cento e trinta e oito pessoas entre pequenos grandes e dezertados na Aldeya de Santa Rita da Pedreira cetenta e oito mortos, dezertados vinte e três $[. . .]^{14}$

Algumas listagens não se limitavam a pontuar os números de mortos, como no caso daquela produzida pelo frei Apolinário da Natividade, que transcreveu o nome de 438 falecidos da Missão de Jesus do Igarapé Grande:

Da gente q falesceo do Contagio em esta Missão de Jesus do Igarapé Grande [...] Hilavia, Jacoicá, Catherina, Domingos, Izidoro [...] Certifico eu Missionário abaixo assignado q revendo o livro que nesta Missão do Menino Jesus do Igarapé Grande serve dos defuntos digo dos assentos dos defuntos nelle achei serem estes assima os q desde de novembro de

\footnotetext{
12 Arquivo Histórico Ultramarino de Portugal, Projeto Resgate, Capitania do Grão-Pará, 15 de setembro de 1750.

${ }^{13}$ Arquivo Histórico Ultramarino de Portugal, Projeto Resgate, Capitania do Grão-Pará, 15 de setembro de 1750.

14 Arquivo Histórico Ultramarino de Portugal, Projeto Resgate, Capitania do Grão-Pará, 15 de setembro de 1750.
} 
1747 em q principiou o contagio nessa Missão apresenta terem falecidos da vida prezente em fe do q mandei passar a presente certidão por mim assignada [...] in verbo sacerdotis. Missão de Jesus 20 de agosto de 1750. Missionario Frei Apolinario da Natividade. ${ }^{15}$

Assim, as listagens se sucediam: ora com mais e ora com menos detalhes, mas apresentando sempre a preocupação de quantificar o número de mortos pela epidemia. 0 trabalho inicial da presente pesquisa foi transcrever todas as listagens e tabular suas informações no software Excel, possibilitando totalizar os mortos arrolados, o que incluía a delimitação por localidade. Em alguns casos também eram vinculadas informações como nome, sexo e idade. Com os dados tabulados, chegou-se à seguinte soma: 13.146 mortos, mais 392 desertados. Um número bem diferente dos 40.000 apresentados pelo governador Francisco Pedro Gurjão.

O problema é que, entre os lugares listados, não figurava a freguesia da Sé - a mais populosa da capitania. 0 número de mortos na Sé foi encontrado em outro documento, datado de 16 de maio de 1750 e anexado a um parecer do Conselho Ultramarino acerca da crise de mão de obra no Grão-Pará, que arrolava 3.348 mortos. ${ }^{16}$ Somando-se os números das 80 listagens com os da freguesia da Sé, tem-se um total de 16.494 mortos pelo sarampo.

Para além dos dados do governador Gurjão, dos vereadores de Belém e dos religiosos responsáveis por cerca de 80 povoações indígenas, um memorialista contemporâneo da epidemia vinculou a seguinte informação: "Dezejosos todos de saberem o numero dos mortos, principiarão a extrahir memorias dos Reverendos Parochos [...] com a mayor certeza, excede o numero de quinze mil mortos; sem fazer lembranças dos Certoens, que como vivem incógnitos pela impenetrabilidade dos matos, parece impossível fazer especifica memoria". Aqui cabe uma ressalva: a memória referia-se ao período de maio de 1748 a outubro de 1749, deixando de fora o resto do ano de 1749 e 1750 . E ainda "exceptuando todos os escravos dos Conventos, da Vigia, Cameta, como também das fazendas dos Rios Guamá, Guacará, Moju, Majuaai, Capim, e outros muitos”. ${ }^{17}$

TABELA 1

Números de mortos pelo sarampo, segundo diferentes fontes

Grão-Pará - 1748-1750

\begin{tabular}{lc}
\hline Fontes & Mortos \\
\hline Estimativa do governador Francisco Pedro Gurjão & 40.000 \\
Resumo vinculado pelo governador Francisco Pedro Gurjão & 18.377 \\
Listagens produzidas a partir dos mortos das aldeias e povoações & 16.494 \\
Notícia do Verdadeiro Contágio (1748-1749) & 15.000 \\
\hline
\end{tabular}

Fonte: Projetos Resgate, Grão-Pará, documentos; 13/08/1750, 15/09/1750, 16/05/1750 e "Noticia verdadeyra do terrivel contagio, que desde Outubro de 1748. ate o mez de Mayo de 1749. tem reduzido a notavel consternaçaõ todos os Certões, terras, e Cidade de Bellém, e Graõ Pará, extrahida das mais fidedignas memorias" / [Manuel Ferreira Leonardo].

\footnotetext{
${ }^{15}$ Arquivo Histórico Ultramarino de Portugal, Projeto Resgate, Capitania do Grão-Pará, 15 de setembro de 1750.

${ }^{16}$ Arquivo Histórico Ultramarino de Portugal, Projeto Resgate, Capitania do Grão-Pará, 16 de maio de 1750.

17 "Noticia verdadeyra do terrivel contagio, que desde Outubro de 1748. ate o mez de Mayo de 1749. tem reduzido a notavel consternaçaõ todos os Certões, terras, e Cidade de Bellém, e Graõ Pará, extrahida das mais fidedignas memorias" / [Manuel Ferreira Leonardo].
} 
Assim, têm-se a estimativa de 40.000 do governador Gurjão, a somatória do Resumo de Mortos que foi de 18.377, a quantificação a partir das listagens dos religiosos que correspondeu a 16.494 mortos e a notícia dos 15.000 mortos entre outubro de 1748 e maio de 1749. Para efeito de análise, consideraremos o menor valor associado a todo o período da epidemia (1748-1750), que é de 16.494 mortos - antevendo a possibilidade de uso político, por parte de colonos e administradores, da hipertrofia dos dados.

E o que significariam 16.494 mortos entre 1748 e 1750, quando comparados com a população total da capitania do Grão-Pará?

Aqui temos um grande problema: ausência de dados acerca do total da população da capitania do Grão-Pará nos anos da epidemia, o que nos obriga a trabalhar com dados da população após 1750 - mais uma vez vale destacar que se trata de um período em que a contagem da população não era regular e nem sob diretrizes estatísticas bem definidas.

De acordo com o levantamento feito pelo historiador Robin Anderson, a maior população indígena aldeada da capitania do Grão-Pará, entre 1770 e 1797, não excedeu a 22.000 índios (ANDERSON, 1999). Esse dado foi corroborado por Mauro Coelho (2005), quando faz o levantamento dos índios aldeados entre 1773 e 1798. Os dois autores se apoiam nos Mapas de População produzidos entre 1773 e $1798 .{ }^{18}$ Tal resultado significa que os mortos pelo sarampo (16.494) representariam $75 \%$ da contagem da maior população indígena aldeada entre 1770 e 1797 (22.000).

Mas, para além dos Mapas de População, existem outras contagens, como o Rol dos Confessados de 1765, que pode dar uma ideia do impacto populacional da epidemia. Segundo esse levantamento, a população da capitania (excetuando-se os menores de sete anos, quatro localidades e a capitania do Rio Negro) contabilizava 33.654 pessoas. ${ }^{19}$ Assim, considerando-se os dados do Rol, os mortos pelo sarampo equivaleriam a $49 \%$ da população total de 1765 (incluindo livres e escravos).

Além da alta mortalidade do sarampo, destaca-se que a maioria esmagadora atingida foi de índios - como a própria documentação cita. Mas esse quantitativo deve ser relativizado, pois o alcance do sarampo não foi homogêneo para toda a capitania, considerando-se espaço e tempo. Isso é o que será discutido a seguir e, para tanto, retomam-se as listagens.

\section{Relativizando o impacto}

Das 80 listagens, apenas 16 distribuíram o número de mortos por ano. Nelas, sistematicamente, o ano de 1749 apresentava-se como de maior intensidade de mortes, embora também fossem mencionados os anos de 1748 e 1750 . Houve referência até mesmo a

\footnotetext{
${ }^{18}$ Estes Mapas de População marcam o primeiro esforço de contagem regular da população da América portuguesa, onde o Estado do Grão-Pará e Maranhão ganhou papel de destaque, com uma incipiente contagem em 1772 e uma mais bem estruturada em 1773

19 Arquivo Histórico Ultramarino de Portugal, Projeto Resgate, Capitania do Grão-Pará, 30 de novembro de 1765. A contabilização foi feita a partir do Rol dos Confessados e excluía os seguintes lugares: Marajó, N. Sra. da Conceição da Cachoeira, Vila de Oeiras, São José de Macapá e a capitania do Rio Negro.
} 
1747, como o ano de início do contágio na Missão de Jesus de Igarapé Grande, onde no total faleceram 438 índios. Mas 1749 foi o ano em que mais morreram índios acometidos pelo sarampo. Na listagem da Aldeia de Mortigura, por exemplo, foram indicados 149 índios mortos, sendo 34 homens, 52 mulheres e 63 inocentes (menores de sete anos). Desse total, apenas quatro homens, seis mulheres e cinco inocentes morreram em 1750, enquanto os demais faleceram em 1749. Em Sumauma também houve maior concentração de mortos em 1749 (94 índios). Dos 36 homens falecidos, seis morreram em 1750, dois em 1748 e os demais em 1749.

Além dos anos, há a possibilidade de observar os meses de maior ocorrência de mortes. Alguns religiosos administradores das localidades não apenas informavam o número de óbitos, mas também os respectivos nomes dos índios, ano e mês dos falecimentos. Predominantemente, a maior incidência de morte ocorria em janeiro, fevereiro e março. Tais meses são marcados com as chuvas de "inverno" na Amazônia, sendo o segundo semestre do ano o período de menor intensidade pluviométrica. Ou seja, a sazonalidade das mortes intensificou-se não apenas no ano de 1749 , mas também nos meses de chuva - especialmente janeiro e fevereiro. Isso em parte pode ser explicado pela maior concentração de índios em espaços fechados, o que facilitaria a difusão do vírus. ${ }^{20}$

Como dito anteriormente, os detalhes das listagens permitem pensar a heterogeneidade do alcance da epidemia: de um lado, tem a questão da sazonalidade, que elege ano e meses específicos para a intensificação no número de mortos; de outro, existe a questão espacial, pois a epidemia não atingiu o vasto território do Grão-Pará de uma mesma forma. Apesar de muitas vezes não haver acesso ao total da população da localidade, é possível perceber num rápido olhar a heterogeneidade do impacto da epidemia.

No Resumo dos Mortos foi registrado o número de índios falecidos (7.600) que serviam aos moradores da cidade de Belém. Nas aldeias da Companhia de Jesus, ainda de maneira mais geral, foram indicados 3.363 óbitos. Nas aldeias de Nossa Senhora do Carmo, o número de mortos foi de 2.308. Nas listagens produzidas pelos religiosos, que possibilitam observar de maneira específica as aldeias, têm-se, por exemplo, Grupatuba, com 550 índios falecidos, Nossa Senhora de Caia, com 398 mortos, e Santa Elizeu do Maricuá, com 372 óbitos.

Algumas listagens apresentavam centenas e até mesmo milhares de mortos, mas outras não ultrapassavam dezenas: missão de Pauxi, com três índios mortos; Nossa Senhora do Carmo do Camara (no Rio Negro), com 19 mortos; Santo Antonio do Castelinho (no Rio Negro), com 20 óbitos; Santo Antonio de Inajatiba, com 18 falecimentos; São Joaquim da Caviana, com 16 mortos; Garapiranga, com 19 óbitos; e Nossa Senhora do Carmo do Camará, com 17 mortos. Esses números mostram a diferenciação do alcance da epidemia.

\footnotetext{
$\overline{{ }^{20}}$ Um estudo acerca da relação da propagação do sarampo e a pluviosidade, feito na década de 1940, mostrou que os meses de chuvas da cidade de Belém (janeiro-abril) corresponderiam a 40,5\% das ocorrências de sarampo do ano inteiro, dando maior destaque, enquanto fator principal de aumento de contágio, ao ajuntamento de indivíduos num mesmo espaço (BARRETO, 1948, p. 732).
} 
Embora, na maioria das vezes, não se teve acesso à população total das aldeias, o número de falecimento aponta para o fato de que algumas localidades sofreram mais com a mortalidade causada pelo sarampo.

Das 80 listagens, nove indicaram a população total, possibilitando observar que morreram $27 \%$ dos índios no Convento de Santo Antonio, 71\% no Convento de Gurupá, $52 \%$ no Hospício de São José de Belém, 31\% em São Joaquim da Caviana, 30\% em Acarapy, $41 \%$ em Nossa Senhora da Conceição das Mangabeiras, 58\% em São Francisco das Goyanazes, 66\% em São Francisco de Caya, e 60\% em Nossa Senhora do Igarapé Grande. Aqui também é possível reforçar a ideia de uma heterogeneidade do alcance da epidemia, mesmo considerando o número total da população das aldeias e lugares. ${ }^{21}$ Observa-se, ainda, que Nossa Senhora da Conceição das Mangabeiras, São Francisco das Goyanazes, São Francisco de Caya e Nossa Senhora do Igarapé Grande eram aldeias da Província do Marajó. Ou seja, numa mesma região, como o Marajó, verificam-se diferenças no impacto da mortalidade da epidemia.

Esses dados ajudam a problematizar a existência de uma razão constante de mortalidade do sarampo na população autóctone da Amazônia e, ao mesmo tempo, revelam um dos limites da presente análise: não foram explorados os fatores que interferiram na produção de diferenciados percentuais de mortos.

Assim, entre 1748 e 1750, a capitania do Grão-Pará foi palco de uma epidemia de sarampo, que deixou um rastro de mortes e uma memória do desespero. A alta mortalidade imposta pela doença atingiu fundamentalmente a população indígena, como aponta a documentação pesquisada. Aliás, deve-se destacar que epidemias de sarampo e varíola não eram novidades na Amazônia e, em geral, tinham maior difusão entre os índios. No entanto, a propagação da epidemia não alcançou a região de maneira homogênea, apresentando variações nos meses, anos e no número de mortos em diferentes povoações indígenas. Concomitantemente, o então governador do Estado do Maranhão e Grão-Pará e os vereadores da cidade de Belém exigiam da Coroa uma solução para o principal efeito da epidemia: crise na oferta de mão de obra.

\section{Os africanos}

Desde meados do século XVII, moradores do Estado do Maranhão reivindicavam a entrada de escravos negros. As justificativas para o pedido eram duas. A primeira estava relacionada à solução do problema da escravização e do uso da força do trabalho indígena, o que constantemente opunha de um lado os moradores e do outro os religiosos, em especial os jesuítas. A segunda justificativa estava atrelada à solução das demandas e da qualidade da mão de obra, em que o Brasil açucareiro emergia como referência (CHAMBOULEYRON, 2004, p. 102). Entretanto, mesmo aparecendo como uma possibilidade de mão de obra,

\footnotetext{
${ }^{21}$ Arquivo Histórico Ultramarino de Portugal, Projeto Resgate, Capitania do Grão-Pará, 15 de setembro de 1750.
} 
a escravidão africana foi utilizada de maneira incipiente ao longo do século XVII, o que se deveu, em parte, à própria condição econômica dos moradores, que não tinham recursos para adquirir escravos (CHAMBOULEYRON, 2004, p. 102). A mudança nessa tendência aconteceu no reinado de $D$. José $I$.

A Coroa mantinha-se informada acerca da mortalidade causada pelo sarampo e tinha clareza que a epidemia poderia afetar a organização da utilização da mão de obra indígena e exigir a inserção de outros grupos de trabalhadores, notadamente os escravos africanos. Isso fica claro na instrução secreta que o novo governador do Maranhão, Francisco Mendonça Furtado (irmão do Marquês de Pombal), recebeu diretamente do rei de Portugal: "a Epidemia que matou tantos Indios, os anos passados; dá occasião a mudarem de método, e facilitar-se a pratica do que vos acima aponto, com o qual os Indios possão gozar da sua liberdade nos poucos que Restão daquele grande contagio". Ainda segundo o monarca, a ocasião era para efetivar o combate aos "excessos” na escravização indígena. Ele reforçava que a liberdade dos indígenas já havia sido matéria de "varias leys pelos Senhores Reys meos Predecessores”. Era necessário persuadir os moradores do Estado do Maranhão e Grão-Pará "a que se sirvam de Escravos Negros".22

Em geral a documentação produzida na época aponta para aceitação do impacto da mortalidade da epidemia e a necessidade de medidas que atenuassem a crise de mão de obra por ela instalada. Nos dois lados do Atlântico, moradores e autoridades reivindicavam mais "braços" para combater a decadência que assolava a produção do Estado do Grão-Pará e Maranhão.

Entretanto havia tensão a respeito do projeto que deveria pautar a solução da demanda de mão de obra. De um lado postavam-se o rei D. José I, o Conselho Ultramarino, o Marquês de Pombal e o seu irmão. Esse grupo apostava numa "solução externa", ou seja, que significaria a inserção de escravos vindos da África. A proposta pautava-se na criação de uma Companhia de Comércio do Grão-Pará e Maranhão, financiada pelo capital privado, que deveria fomentar o tráfico negreiro para a Amazônia (SOUSA JR., 2012, p.157-8; CARREIRA, 1969).

O outro projeto era defendido, na maioria das vezes, sob o anonimato, pois iria de encontro às determinações reais. Essa proposta apontava para uma "solução interna", ou seja, na ratificação da escravidão indígena, apoiando-se na autorização e financiamento de Tropas de Resgate e no combate aos mocambos - abrigos de muitos índios que fugiram das roças dos moradores. A argumentação desse grupo baseava-se no limite de oferta de escravos africanos, no custo de aquisição e manutenção desses escravos e na inexperiência que teriam na lida com a rotina produtiva da Amazônia.

O impacto do sarampo na organização econômica da capitania do Grão-Pará já havia sido mencionado pelo governador Francisco Pedro Gurjão, em abril de 1749, quando solicitou a intervenção da Coroa para solucionar a crise de mão de obra. No esforço de

$\overline{22}$ Biblioteca Nacional de Portugal, Coleção Pombalina, F.348, 30 de maio de 1751. 
convencimento, o governador Francisco Pedro Gurjão apresentava ao Conselho Ultramarino as repercussões diretas da ausência de mão de obra: a diminuição das "rendas de Sua Magestade" e "potencias estrangeyras, q'se poderão aproveytar da debilidade das nossas forças para se animarem a algum projecto q" perturbe a nossa conservação". ${ }^{23}$ Para evitar a "ruína” da capitania do Grão-Pará, incluindo a possibilidade de uma invasão estrangeira, o próprio governador apontava uma solução:

fazer neste anno, e nos tres ou quatro seguintes alguas carregaçoens de escravos da Costa da Mina, Guiné, e llhas de Cacheu, com ordem de serem nestas Capitanias despendidos pelos Moradores à proporção das Sua Lavouras, e necessidade, ficando obrigados as que os receberem a pagar logo o custo à Real Fazenda tendo cabedal pronto, e os q não tiverem Hypothecarem as próprias fazendas ao tal pagamento. ${ }^{24}$

Entretanto, Francisco Pedro Gurjão não acreditava na solução por ele mesmo apontada. Em carta ao secretário Pedro Francisco da Encarnação, o governador Gurjão diz textualmente que mentiu: "na dita carta não fallo em Tropa [de Resgate], por q sey que no Conselho [Ultramarino] falarse hoje nesta matéria he, além de infrutífera deligencia, arriscar muito o credito, pois entendem que so serve para utilidade dos q governão, e por esta cauza só aponta o meyo dos prettos da Costa da Mina".25

Em suas próprias palavras, o governador mentiu deliberadamente para o Conselho Ultramarino não em relação ao impacto da epidemia de sarampo, mas sim quanto à solução para a crise de mão de obra por ela causada: ratificou a estimativa de 40.000 mortos. Ele também afirmou que omitiu deliberadamente o fato de apoiar a intensificação das Tropas de Resgate como solução para a demanda de "braços". E o fez, ainda segundo ele, para não abalar sua imagem diante do Conselho Ultramarino - que combatia a escravidão indígena e fomentava a africana. Continuando sua argumentação, ele afirmava que a medida adotada pela Coroa não resultaria em solução, pois o número de africanos seria insuficiente para atender a todos os moradores e pelo fato de que alguns serviços somente os índios eram capazes de executar. ${ }^{26}$ Defensor da solução interna, Francisco Pedro Gurjão reforçava sua argumentação afirmando que somente as Tropas de Resgate poderiam por fim às incursões dos holandeses no sertão do Rio Negro.

A mentira e o anonimato eram formas de proteção contra possíveis punições impostas pela Coroa àqueles que se posicionassem contra seu projeto. Uma carta anônima, escrita provavelmente no primeiro ano de governança de Mendonça Furtado, apontava que a solução do rei era "inapropriada". 0 autor se coloca permanentemente contra a vinda de africanos e diz que a proibição das Tropas de Resgate só piorava a situação da capitania: primeiro, pelo preço e quantidade de escravos africanos necessários, que não dariam para atender à demanda de todos os moradores; e segundo, porque "os pretos não servem mais

\footnotetext{
${ }^{23}$ Arquivo Histórico Ultramarino de Portugal, Projeto Resgate, Capitania do Grão-Pará, 26 de abril de 1749.

${ }^{24}$ Arquivo Histórico Ultramarino de Portugal, Projeto Resgate, Capitania do Grão-Pará, 26 de abril de 1749.

${ }^{25}$ Arquivo Nacional da Torre do Tombo/Portugal, Ministério do Reino, maço 597, Doc. 02.

${ }^{26}$ Arquivo Nacional da Torre do Tombo/Portugal, Ministério do Reino, maço 597, Doc. 02.
} 
que para trabalharem com hua fouce, e machado dandolhe bem de comer, por não terem habilidade para caçar, e pescar, como fazem os tapuyas para sy, e seus senhores, q estando nas suas fazendas se sustentão e toda família de peyxe e caça". ${ }^{27}$ A experiência que os índios tinham na lida diária da capitania aparecia como grande trunfo para a autorização das Tropas de Resgate. Os africanos teriam um custo de manutenção e não poderiam sustentar os moradores com peixe e caça. Ainda no primeiro ano das atividades da Companhia de Comércio do Grão-Pará e Maranhão (1756), já se fazia necessário normatizar os preços e a distribuição dos escravos africanos vendidos na praça de Belém, pois havia conflitos que envolviam a aquisição de escravos africanos e os moradores da cidade. ${ }^{28}$

Solução externa versus solução interna; qual foi o resultado do confronto entre os dois projetos? Para responder a essa pergunta devem ser consideradas a criação da Companhia de Comércio do Grão-Pará e Maranhão, a legislação que regulava o uso do trabalho indígena (Diretório) e a entrada de escravos africanos até 1778, ano da liquidação da Companhia de Comércio. Mas isso não basta: é necessário ponderar acerca da distribuição de escravos africanos na capitania do Grão-Pará. Os números apontam para algumas localidades onde a escravidão africana se tornou presente e efetiva, mas também indicam outras regiões onde a mão de obra continuou a ser essencialmente indígena.

A média anual de escravos que entraram no Grão-Pará, entre 1680 e 1698, foi de 47 cativos, diminuindo para menos de 25 escravos entre 1702 e 1755. Essa média aumentou significativamente com a criação da Companhia de Comércio do Grão-Pará e Maranhão, passando para 801 cativos por ano entre 1756 e 1778, o que representou um novo patamar no volume de escravos africanos inseridos na capitania (BEZERRA NETO, 2012, p. 49; CHAMBOULEYRON, 2004, p. 102).

Mas aqui é necessário chamar a atenção para um ponto: não se pode considerar o impacto populacional da escravidão africana de maneira homogênea. Mesmo analisando apenas os escravos introduzidos pela Companhia, emerge o problema da distribuição de africanos ao longo do tempo. Entre 1756 e 1778, o abastecimento variou por ano. Partindo do total de 17.627 africanos introduzidos pela Companhia, há uma grande variação ao longo do tempo: por exemplo, em 1769 entraram apenas 181 escravos; já em 1762 a entrada foi de 2.005 africanos (BEZERRA NETO, 2012, p. 210-213). Isso pode evidenciar uma oscilação no abastecimento, criando variações demográficas ao longo do período da atuação da Companhia: 2.005 escravos significavam um contingente superior à população total da maior parte das vilas do Grão-Pará.

Outro aspecto que pode ser destacado é a distribuição espacial dos escravos africanos, tendo como referência a contagem populacional do Grão-Pará de 1777, pois foi a contagem de população mais próxima do fim das atividades da Companhia. Nela, a freguesia da Sé de Belém aparece com 2.000 escravos distribuídos em 547 fogos, criando uma média aproxi-

\footnotetext{
${ }^{27}$ Arquivo Nacional da Torre do Tombo/Portugal, Ministério do Reino, maço 597, Doc. 03.

${ }^{28}$ Biblioteca Nacional de Portugal, Coleção Pombalina, F.321, f. 178. Testemunho do bispo Miguel de Bulhões, que substituiu Mendonça Furtado enquanto este viajava para a capitania do Rio Negro.
} 
mada de quatro escravos por fogo (domicílio). E mais, se comparada com a população de livres (excetuando os índios) de 4.612 pessoas, tem-se uma média de dois livres para um escravo. Em outras freguesias essa proporção ganha novos contornos. A vila de Cametá, às margens do Rio Tocantins e notadamente marcada pela presença da agricultura e de Engenhos, tinha 4.120 livres (excetuando os índios) para 1.192 escravos, numa proporção superior a três livres por um escravo.

Ainda segundo o mesmo Mapa de População do ano de 1777, das 75 freguesias e lugares, ${ }^{29} 18$ povoações não possuíam nenhum escravo e 15 tinham menos de dez escravos. Todas as 22 "povoações de brancos" apresentavam um número superior a dez escravos, embora entre elas houvesse uma variação de 2.000 escravos para a Sé e 27 para Bujarú. Tais diferenças devem considerar o modelo produtivo da região e o poder econômico e político dos proprietários, além da intensidade do impacto do sarampo e da disponibilidade de índios para o trabalho.

Fortalecendo o argumento da variação espacial de distribuição da escravaria, pode-se considerar a freguesia de Nova Mazagão (no atual Amapá). Esta localidade atrelou seu desenvolvimento populacional à agricultura, em especial ao arroz, e teve como um dos principais obstáculos para o aumento da produção a oferta de mão de obra: "a flutuação maior foi de índios destribalizados que chegavam a representar $80 \%$ dos trabalhadores" (MARIN, 2005, p. 89-90). A freguesia vizinha, Macapá, tinha uma menor dependência da força de trabalho indígena: embora tivesse menos “cabeças de família” que Mazagão, possuía $50 \%$ a mais de escravos adultos. E ainda, apenas metade dos colonos se beneficiava de escravos e créditos ofertados pela Companhia, o que, na prática, significava um conjunto de desigualdades relacionadas ao lugar político entre colonos, a dinâmica produtiva de freguesias vizinhas e a própria distribuição da escravaria africana - seja entre freguesias, seja entre colonos (MARIN, 2005, p. 89-90).

Assim, é possível pensar inicialmente que, entre 1757 e 1777, o Estado do Grão-Pará e Maranhão assistiu a um novo movimento populacional: a entrada de africanos por meio da Companhia de Comércio trouxe um número significativo de escravos para a Amazônia. Mas aqui não se deve sucumbir ao erro de considerar essa mudança homogênea.

\section{Considerações finais}

Entre 1748 e 1750, a capitania do Grão-Pará foi assolada por uma epidemia de sarampo. A intensidade da doença foi traduzida na morte de mais de 16 mil índios na região. Sendo o indígena a principal força de trabalho utilizada pelos moradores (colonos), religiosos e administradores locais, a alta mortalidade significou a intensificação do conflito histórico acerca do controle da mão de obra na Amazônia.

\footnotetext{
${ }^{29}$ Incluindo Nova Mazagão e lugares de índios anexos a Bragança, Ourém e Gurupá.
} 
O esforço de efetivar uma solução para a carência de trabalhadores e as tensões políticas internas entre colonos, religiosos e administradores matizaram dois projetos. 0 primeiro buscava intensificar a exploração e escravização dos índios. 0 segundo baseava-se na inserção do trabalho escravo africano, por meio do tráfico negreiro fomentado pela criação da Companhia de Comércio do Grão-Pará e Maranhão.

A análise dos Mapas de População dos anos finais do reinado de D. José I mostrou, como resultado dessa disputa, a vitória (ou derrota) pontual dos dois projetos. Ou seja, para algumas localidades da imensa capitania do Grão-Pará, a presença de escravos africanos aumentou significativamente, enquanto para outras vilas ou povoações, mesmo após a epidemia de sarampo e da criação da Companhia de Comércio, a escravidão africana continuava insipiente ou nula.

\section{Referências}

ANDERSON, R. Colonization as exploitation in the Amazon rain forest, 1758-1911. Florida: University Press of Florida, 1999.

ANGELO-MENEZES, M. N. O sistema agrário do Vale do Tocantins colonial: agricultura para consumo e para exportação. Projeto História. São Paulo, n. 18, 1999.

BANDEIRA, M. L. Demografia. Lisboa: Escolar Editora, 2004.

BARRETO, J. B. Contribuição ao estudo da distribuição sazonal de febres eruptivas. Memórias do Instituto Oswaldo Cruz, v. 46, n. 4, p.719-746, 1948.

BEZERRA NETO, J. M. Escravidão negra no Grão-Pará (séc. XVII-XIX). 2. ed. Belém: Pakatatu, 2012.

BICALHO, M. F. A cidade e o império. Rio de Janeiro: Civilização Brasileira, 2003.

CANCHO, M. R. La villa de Cáceres en el siglo XVIII (Demografia y sociedad). Cáceres: Universidad de Extremadura, 1981.

CARREIRA, A. As Companhias Pombalinas de Navegação, comércio e tráfico de escravos entre a costa africana e o Nordeste brasileiro. Porto: Imprensa Portuguesa, 1969.

CARVALHO JR., A. Índios cristãos no cotidiano das colônias do Norte. Revista de História da USP, n. 168, p. 69-99, 2013.

CHAMBOULEYRON, R. Suspiros por um escravo de Angola: discurso sobre a mão-de-obra africana na Amazônia Seiscentista. Revista Humanitas, v. 20, n. 1/2, p. 99-111, 2004.

CHAMBOULEYRON, R. et al. Formidável contágio: epidemias, trabalho e recrutamento na Amazônia colonial (1660-1750). Revista História, Ciências e Saúde-Manguinhos, v. 18, n. 4, p. 987-1004, 2011.

COELHO, M. Do sertão para o mar: um estudo sobre a experiência da América, a partir da Colônia; o caso do Diretório dos Índios (1750-1798). Tese (Doutorado em História) - Universidade de São Paulo - USP, São Paulo, 2005.

COIMBRA JR., C. O sarampo entre sociedades indígenas brasileiras e algumas considerações sobre a prática da saúde pública entre estas populações. Cadernos de Saúde Pública, v. 3, n. 1, p. 22-37, jan./mar. 1987.

DANIEL, J. Tesouro descoberto no Rio Amazonas. Anais da Biblioteca Nacional, v. 95, tomo I, 1975. 
DEAN, W. Las poblaciones indígenas del litoral brasileño de São Paulo a Rio de Janeiro. Comercio, esclavitud, reducción y extinción. In: SANCHEZ-ALBORNOZ, N. Poblacion y mano de obra em America Latina. Madrid: Alianza America, 1992, p. 25-52.

DOBYNS, H. Estimating aboriginal populations: an appraisal of techniques with a new hemispheric estimate. Current Anthopology, v. 7, n. 4, p. 395-416, 1966.

FERREIRA, A. Diário de viagem filosófica pela capitania de São José do Rio Negro. 1781. Disponível em 〈http://www.filologia.org.br/pereiA/textos/diario_do_rio_negro_1.pdf〉. Acesso em: 15 maio 2014.

FERRO, J. P. A população portuguesa no final do antigo regime (1750-1815). Lisboa: Editorial Presença, 1995.

GUERRA, F. The European-American exchange. History and Philosophy of the Life Sciences, v. 15, n. 3, p. 313-327, 1993.

GLASS, D. V.; EVERSLEY, D. E. C. Population in history: essays in historical demography. London: Edward Arnold, 1965.

GUZMÀN, D. de A. Guerras na Amazônia do século XVIII: resistência indígena à colonização. Belém: Estudos Amazônicos, 2012.

IMIZCOZ, J. M. Actores, redes, processos: reflexiones para uma história más global. Revista da Faculdade de Letras História, III série, v. 5, p. 115-40, 2004.

LIVI-BACCI, M. The depopulation of Hispanic America after the conquest. Population and Development Review, v, 32, n. 2, p. 199-232, 2006. Disponível em <http://onlinelibrary.wiley. com/doi/10.1111/j.1728-4457.2006.00116.x/pdf>. Acesso em: 09 set. 2014.

A concise history of world population. 3. ed. Oxford: Blackwell, 2001.

Amazzonia: L'imperio dell'acqua (1500-1800). Bologna: Il Mulino, 2012.

MACLACHLAN, C. African slave trade and economic development in Amazonia, 1700-1800. In: TOPLIN, R. B (Ed.). Slavery and race relations in Latin America. Westport: Greenwood Press, 1974.

MAGALHAES, J. R. Labirintos brasileiros. São Paulo: Alameda, 2011.

MARIN, R. A. Agricultura no delta do rio Amazonas: colonos produtores de alimentos em Macapá no período colonial. Novos Cadernos NAEA, v. 08, n. 1, p. 73-114, jun. 2005.

MAXWELL, K. Marquês de Pombal. Rio de Janeiro: Paz \& Terra, 1996.

MENDONÇA, M. C. de. A Amazônia na era pombalina. Brasília: Senado Federal, 2005.

MELO FILHO, D. A epidemiologia, os valores e o significado de paradigma. Cad. Saúde Pública, v. 13, n. 4, p. 761-766, out.-dez. 1997.

MOREDA, V. P. Las crisis de mortalidad en la España interior. Siglos XVI-XIX. Madrid: Siglo XXI de España, 1980.

NADALIN, S. História e demografia. Campinas: Abep, 2004.

PAGLIARO, H.; AZEVEDO, M.; SANTOS, R. Demografia dos povos indígenas no Brasil: um panorama crítico. Rio de Janeiro: Ed. Fiocruz, 2005.

REAY, B. Microhistories: demography, society and culture in rural England, 1800-1930. Cambridge: Cambridge Press, 1996.

RODRIGUES, M. I. 0 governador Francisco Xavier de Mendonça Furtado no Grão-Pará. Dissertação (Mestrado em História e Cultura do Brasil) - Faculdades de Letras, Universidade de Lisboa, Lisboa, 1997. 
ROLLER, H. Migrações indígenas na Amazônia do século XVIII. In: CANCELA, C.; CHAMBOULEYRON, R. (Orgs.). Migração na Amazônia. Belém: Ed. Açaí/Centro de Memória da Amazônia, 2010, p. 27-40.

SAHLINS, M. Ilhas de história. Rio de Janeiro: Zahar, 1990.

SANTOS, F. V. O governo das conquistas do Norte: trajetória administrativa do Estado do GrãoPará e Maranhão (1751-1780). Tese (Doutorado em História Social) - Universidade de São Paulo - USP, São Paulo, 2008.

SCOTT, A. A historiografia do Cambridge Group: contribuições ao estudo da população, da família e do grupo doméstico. Revista de Estudos Amazônicos, v. IX, n. 1, 2013.

SILVA, J. M. A. 0 modelo pombalino de colonização da Amazônia. Disponível em: 〈http://www. uc.pt/fluc/iheu/artigos/modelopombalino>. Acesso em: 15 mar. 2014.

SOBRAL, M. da L. A intervenção da Companhia Geral do Grão-Pará e Maranhão (1755-1778). Dissertação (Mestrado em História dos Descobrimentos e da Expansão Portuguesa) - Faculdades de Letras, Universidade de Lisboa, Lisboa, 2004.

SOUZA JR., J. A. Tramas do cotidiano: religião, política, guerra e negócios no Grão-Pará do Setecentos. Belém: Ed. UFPA, 2012.

UGARTE, A. Sertões de bárbaros. Manaus: Ed. Valer, 2009.

VAINFAS, R. Dicionário do Brasil Colonial (1500-1808). Rio de Janeiro: Objetiva, 2000.

WRIGLEY, E.; SHOFIELD, R. The population history of England 1541-1871. London: Edward Arnold, 1981.

\title{
Sobre os autores
}

Antonio Otaviano Vieira Junior é historiador, doutor em História e professor da Universidade Federal do Pará - UFPA.

Roberta Sauaia Martins é historiadora e mestranda do Programa de Pós-Graduação em História Social da Amazônia, da Universidade Federal do Pará - UFPA.

\section{Endereço para correspondência}

\author{
Antonio Otaviano Vieira Junior \\ Rua Joly Braga Santos, Lote F, 1 을 direito \\ 1600-123 - Lisboa, Portugal \\ Roberta Sauaia Martins \\ Travessa Nove de Janeiro, 2076, apt. 802 \\ 66060-260 - Belém-PA
}

\section{Abstract}

Measles epidemic and slave work in Grão-Pará (1748-1778)

The paper discusses the population impact of the measles epidemic (1748-1750) in Grão-Pará (a captaincy of the Portuguese Empire, now northern Brazil) and its relation to the process of insertion of African slave labor. The analysis is based on the documentation produced in the 18th century, including official correspondence, essays, memoirs, population maps and lists of 
those killed by the epidemic. The serial documentation was entered into a database, created from 80 lists of those killed by measles, which allowed an analysis of the demographic impact of the disease. Concomitantly, the population count of the captaincy's towns and villages from the third quarter of the 18th century composed a second database and facilitated understanding of the internal distribution of African slaves. The point of intersection between the databases is the set of historical administrative documents, which addresses the effects of the epidemic and the possible solutions to the labor crisis - caused by the high mortality of indigenous peoples. The study shows not just measles mortality, but also the construction of a policy for the insertion of African slaves in the region. As such, the text is divided into two parts: the first deals with the epidemic itself, its presence in the city Belém, the importance of indigenous labor for the colonists, the number of deaths and the distribution of mortality in terms of space and seasonality (months and years). The second part discusses the fundamental struggle between projects that addressed the demand for labor, the policy of insertion of African slaves as a means to combat the high mortality of measles, and the distribution of these slaves in the captaincy.

Keywords: Measles. Indians. Slaves. Amazonia. Grão-Pará.

\section{Resumen}

\section{Epidemia de sarampión y trabajo esclavo en el Gran Pará (1748-1778)}

En el artículo se analiza el impacto sobre la población de la epidemia de sarampión que se produjo en la capitanía del Gran Pará entre 1748-1750 y su relación con el proceso de inserción de la mano de obra de los esclavos africanos. El análisis se basa en documentación producida durante el siglo XVIII, recogida en varios archivos brasileños y portugueses, que incluye correspondencia oficial, crónicas, memorias, mapas y listados de muertos por la epidemia. La documentación serial se incluyó en una base de datos construida a partir de 80 listados de muertos por el sarampión, lo que permitió un análisis de los efectos demográficos de la epidemia. Al mismo tiempo, el recuento de la población de las ciudades y pueblos de la capitanía en el tercer cuarto del siglo XVIII compuso una segunda base de datos, y ayudó a la comprensión de la distribución interna de los esclavos africanos. El punto de intersección entre las bases de datos lo constituye el conjunto de la documentación administrativa histórica que se ocupa de los efectos de la epidemia y las posibles soluciones para la crisis de la mano de obra causada por la alta mortalidad de los indígenas. El estudio no solo se propone abordar la mortalidad causada por el sarampión, sino también la construcción de una política para la inserción de los esclavos africanos en la región. Por lo tanto, se aborda la epidemia en Belém, la importancia del trabajo indígena para los colonos, el número de muertos y la distribución de la mortalidad considerando el espacio y la estacionalidad (meses y años). También se discute la lucha entre proyectos para subsanar la demanda de mano de obra generada por la alta mortalidad causada por el sarampión, y la política de inserción de los esclavos africanos como un mecanismo para combatir la escasez de trabajadores, así como la distribución de estos esclavos en la capitanía.

Palabras clave: Sarampión. Indios. Esclavos. Amazonía. Gran Pará. 
